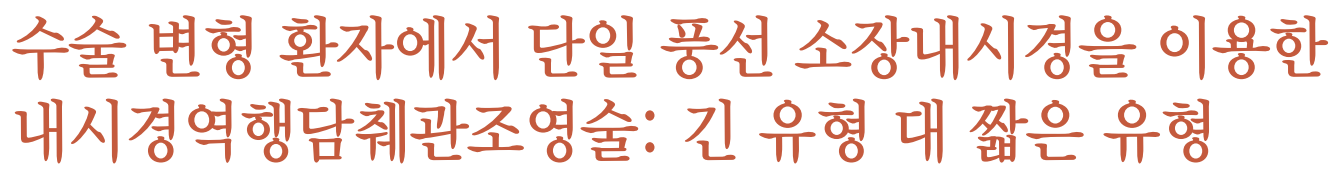

전남대학교 의과대학 내과학교실

박창환

\title{
Single Balloon Enteroscopy-Guided Endoscopic Retrograde Cholangio- pancreatography in Surgically Altered Anatomy: Long vs. Short Type
}

\author{
Chang-Hwan Park \\ Department of Internal Medicine, Chonnam National University Medical School, Gwangju, Korea
}

Traditionally, enteroscopy-guided endoscopic retrograde cholangiopancreatography (ERCP) was considered as troublesome procedure with high risk of complications in patients with surgically altered anatomy (SAA). However, recent studies have suggested that it might not have to be a foregone conclusion. In addition, various enteroscopes have been used for enteroscopy-guided ERCP in patients with SAA showing promising results. Among them, long type single balloon enteroscopes (SBE) have mostly been used for enteroscopy-guided ERCP in Korea. Recently, short type SBE can come in handy all around. Two major points should be considered when to choose between long type and short type SBE in SAA. First, it is the figurative difference between the two types of SBE that effects on actual results of enteroscopy-guided ERCP. Second, it is clinical studies using short type and/or long type SBE for enteroscopy-guided ERCP in patients with SAA. Conclusively speaking, short type SBE should be considered at first for enteroscopy-guided ERCP in most patients with SAA.

Korean J Pancreas Biliary Tract 2021;26(3):181-185

Keywords: Cholangiopancreatography, endoscopic retrograde; Digestive system surgical procedures; Single-balloon enteroscopy $\begin{array}{ll}\text { Received } & \text { Apr. 19, } 2021 \\ \text { Revised } & \text { May 19, } 2021 \\ \text { Accepted } & \text { May 24, } 2021\end{array}$

Corresponding author: Chang-Hwan Park

Division of Gastroenterology, Department of Internal Medicine, Chonnam National University Medical School, 42 Jebong-ro, Donggu, Gwangju 61469, Korea

Tel. +82-62-220-6296 Fax. +82-62-228-1330

E-mail; p1052ccy@hanmail.net

ORCID: https://orcid.org/0000-0002-2995-8779

This is an Open Access article distributed under the terms of the Creative Commons Attribution Non-Commercial License (http:// creativecommons.org/licenses/by-nc/3.0/) which permits unrestricted non-commercial use, distribution, and reproduction in any medium, provided the original work is properly cited.

Copyright @ 2021 by The Korean Journal of Pancreas and Biliary Tract

\section{서 론}

정상 해부 구조를 가진 환자에서 내시경역행담췌관조영술 (endoscopic retrograde cholangiopancreatography, ERCP)의 성공률은 일반적으로 95\%를 상회한다. ${ }^{1}$ 그렇지만 수술로 인해 변형된 해부 구조를 갖고 있는 환자에서 일반 내시경 및 부속기구를 이용한 $\mathrm{ERCP}$ 의 성공률은 $51 \%$ 로 낮게 보고된 연구도 있다. ${ }^{2}$ 수술 변형이 있는 환자에서 일반 십이지장경 및
부속 기구를 이용한 ERCP의 성적이 낮은 이유는 다양하다. 첫째, 근치전체위절제술(radical total gastrectomy) 및 날문보존이자샘창자절 제술 (pylorus-preserving pancreaticoduodenectomy)과 같은 변형된 해부 구조를 갖는 환자에서 바터 팽대부 또는 담관 공장 문합부까지의 삽입로가 너무 길어 일반 십이지장경의 유효 길이로는 삽입이 불가능할 수 있다. 둘째, 내시경 삽입 과정에서 소장 및 복막의 유착 및 섬유화로 인한 각형성, 고착 등 다양한 난관을 만나게 된다. 
셋째, 수술로 인한 변형으로 바터 팽대부에서 선택 삽관이 매우 어려울 수 있다. 넷째, 선택 삽관에 성공한 경우에도 적절한 부속 기구가 없어 시술이 어려울 수 있다. ${ }^{3}$ 이 중 $\mathrm{ERCP}$ 성공에 가장 중요한 요소는 삽입 성공률로 알려져 있다. ${ }^{4}$ 따라서, 수술 변형된 환자에서 성공적인 $\mathrm{ERCP}$ 의 성공률을 높이기 위하여 다양한 방법이 연구되었으며, 그중 삽입 성공률을 높일 수 있는 방법으로 십이지장경보다 유효 길이가 긴 소장내시경에 대한 연구가 활발하게 이루어져, 단일 풍선 소장내시경(single balloon enteroscope)의 경우 $74 \%$ 의 성공률이 보고되었다. ${ }^{5}$ 현재까지 사용된 소장내시경의 종류는 매우 다양하여 단일 풍선 소장내시경, 이중 풍선 소장내시경(double balloon enteroscope), 나선형 소장내시경(spiral enteroscope)이 있으며 이중 풍선 소장내시경은 다시 길이에 따라 긴 유형과 짧은 유형이 모두 사용되었다. ${ }^{5-9}$

우리나라에서는 전통적으로 수술 변형이 있는 환자에서 소장내시경을 이용한 $\mathrm{ERCP}$ 는 까다롭고 합병증이 높은 검사로 인식되어 왔다. 따라서 국내에서 소장내시경을 이용한 연구가 매우 제한적이지만 다양한 소장내시경 중 긴 유형 단일 풍선 소장내시경을 이용한 연구에서 바터 팽대부 부위까지 삽입에 성공하였지만 적합한 부속 기구의 부족을 언급하였다. ${ }^{10}$ 국내에 짧은 유형 단일 풍선 소장내시경이 도입되지 않아 이에 대한 증례 및 연구는 전혀 없었으나 2020년 후반에 드디어 국내에 도입됨에 따라 임상에 사용할 수 있게 되었다(Figs. 1, 2). 따라서 국내 췌장담관 내시경 전문가들도 드디어 긴 유형과 짧은 유형

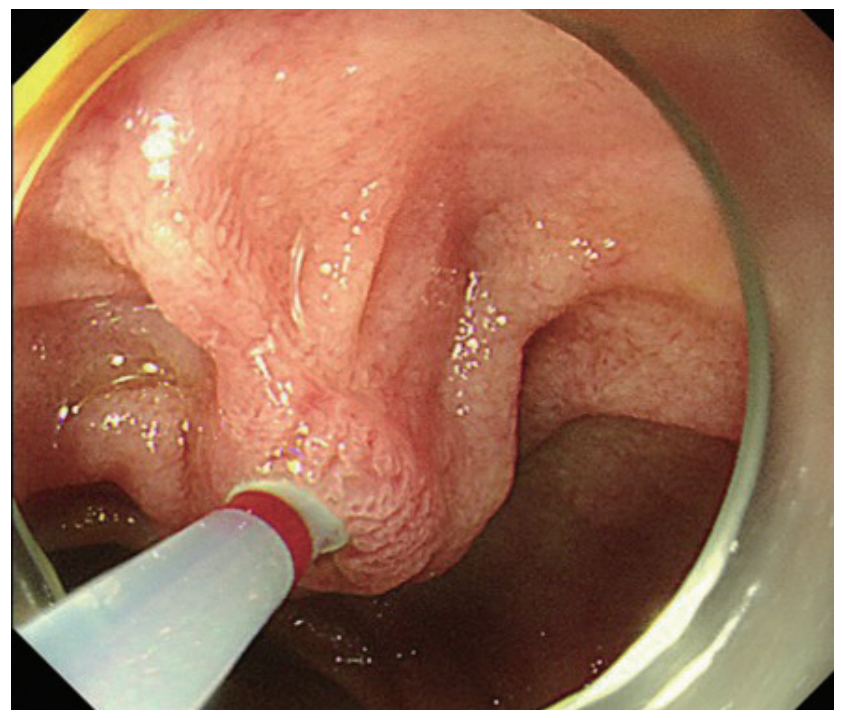

Fig. 1. Endoscopic view shows successful selective common bile duct cannulation using a short type single balloon enteroscope in a patient with prior radical total gastrectomy with Roux-en-Y anastomosis.
단일 풍선 소장내시경을 선택할 수 있는 기회를 갖게 되었다. 그런데 긴 유형과 짧은 유형 단일 풍선 소장내시경을 선택하기 전에 크게 2가지 점을 고려할 필요가 있다. 첫째, 긴 유형과 짧은 유형 사이의 구체적인 차이점이 실제 ERCP에 어떤 영향을 미치냐는 점이다. 둘째, 두 유형의 단일 풍선 소장내시경을 이용한 임상 연구 결과들에 대한 올바른 접근이다. 본고에서는 이 두 가지 점에 대하여 정리해 보고자 한다.

\section{본 론}

\section{1. 긴 유형과 짧은 유형 단일 풍선 소장내시경의 차이점}

긴 유형과짧은 유형 단일 풍선 소장내시경의 가장 큰차이점 중 하나는 유효 길이와 겸자공의 직경이다(Table 1). ${ }^{11}$ 첫째, 긴 유형 단일 풍선 소장내시경의 유효 길이는 $2,000 \mathrm{~mm}$ 이고 짧은 유형 단일 풍선 소장내시경의 유효 길이는 $1,520 \mathrm{~mm}$ 로 약 $480 \mathrm{~mm}$ 차이가 난다. 일반적으로 ERCP 시술에 지장이 없기 위해서는

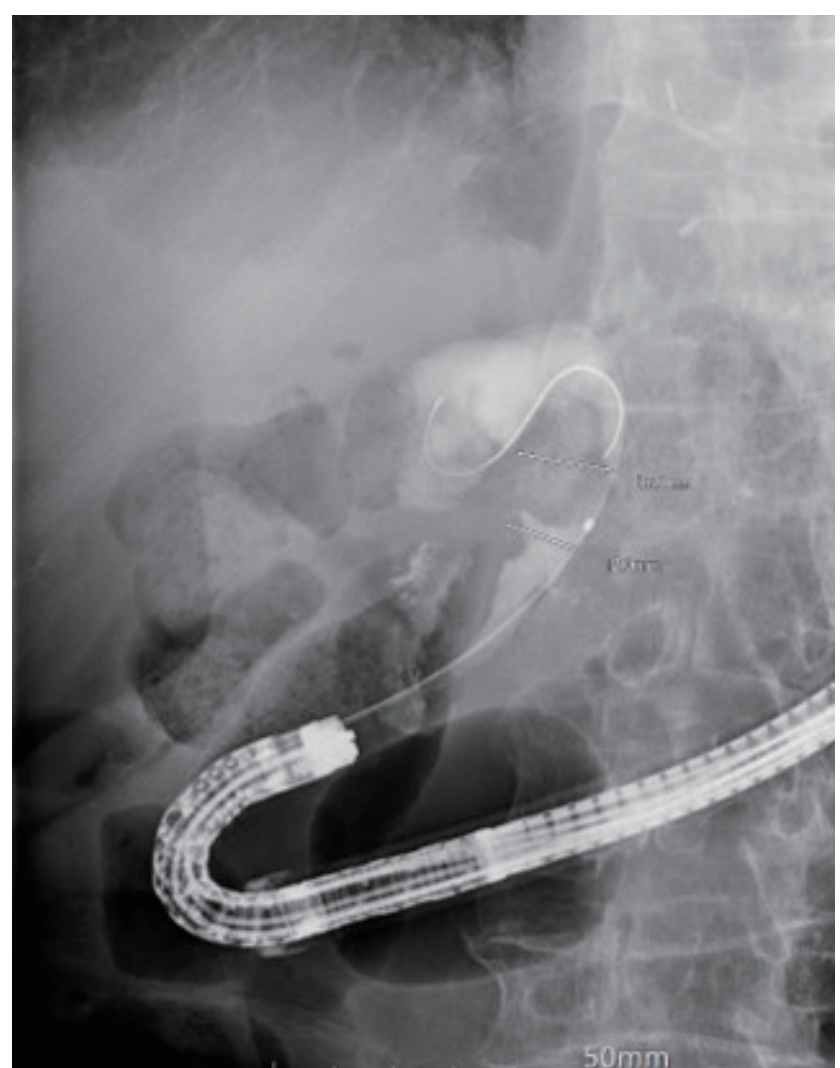

Fig. 2. Fluoroscopic view shows a giant stone as filling defect on cholangiogram which was obtained by using a short type single balloon enteroscope in a patient with prior radical total gastrectomy with Rouxen-Y anastomosis. 
부속 기구의 길이는 내시경의 유효 길이보다 $200 \mathrm{~mm}$ 이상 길어야 사용에 제한이 없다. 따라서 긴 유형 단일 풍선 소장내시경에 사용할 부속 기구는 최소한 $2,200 \mathrm{~mm}$ 길이를 넘어야 한다. 반면 짧은 유형 단일 풍선 소장내시경은 부속 기구의 길이가 $1,720 \mathrm{~mm}$ 만 넘으면 사용에 지장이 없다. 일반적으로 유도선의 길이는 $4,000 \mathrm{~mm}$ 이상이기에 긴 유형 및 짧은 유형 단일 풍선 소장내시경에 사용하는 데는 전혀 제한이 없다. 그러나 카테터 $(2,150 \mathrm{~mm})$ 와 절개도 $(2,000 \mathrm{~mm})$ 는 길이가 짧아 짧은 유형 단일 풍선 소장내시경에서는 사용이 가능하지만 긴 유형 단일 풍선 소장내시경에서는 사용할 수 없다. 긴 유형 단일 풍선 소장내시경에 카테터로 사용 가능한 부속 기구는 대장형 올가미 또는 대장내시경용 주입기의 길이가 $2,300 \mathrm{~mm}$ 로 사용 가능하다. 또한 바터 팽대부 및 담관 공장 문합부를 확장할 계획이라면 대장용 CRE 풍선(Boston Scientific, MA, USA; 2,300 mm)을 카테터 및 확장 목적으로 처음부터 사용해 볼 수 있다. 담석을 제거할 경우 대부분 바스켓(1,900-1,950 mm)은 짧은 유형 단일 풍선 소장내시경 에서 사용이 가능하지만 긴 유형 단일 풍선 소장내시경에서는 사용이 불가능하다. 다행히 lithotomy basket (MTW, Wesel, Germany; 4,000 mm)을 사용하면 긴 유형 단일 풍선 소장내시경에서도 담석 제거가 가능하지만 기계적 쇄석술은 불가능하다. 일반적인 $\mathrm{ERCP}$ 에 사용하는 부속 기구들은 짧은 유형 단일 풍선 소장내시경에 제한 없이 쓸 수 있으나 플라스틱 스텐트를 넣는 경우 추진기 $(1,700 \mathrm{~mm})$ 는 길이가 짧아 사용에 제한이 있다. 따라서 대장형 올가미 카테터 $(2,300 \mathrm{~mm})$ 를 사용하면 해결이 가능하다. 담관형 금속 스텐트는 삽입기 길이가 $1,800 \mathrm{~mm}$ 로 짧은 형 단일 풍선 소장내시경에서는 사용이 가능하지만 긴 유형에서는 사용이 불가능하다. 둘째, 긴 유형 단일 풍선 소장내시경의 겸자공 직경은 $2.8 \mathrm{~mm}$ 이고 짧은 유형 단일 풍선 소장내시경의 겸자공 직경은 $3.2 \mathrm{~mm}$ 로 약 0.4 $\mathrm{mm}$ 차이가 난다. 따라서 7 French $(2.34 \mathrm{~mm})$ 부속 기구는 긴 유형 및 짧은 유형 단일 풍선 소장내시경에 모두 사용이
가능하지만 8.5 French $(2.83 \mathrm{~mm})$ 직경의 부속 기구는 짧은 유형 단일 풍선 소장내시경에서만 사용이 가능하다. 물론 10 French $(3.34 \mathrm{~mm})$ 부속 기구는 두 유형 모두 사용이 불가능하다. 긴 유형 단일 풍선 소장내시경에 7 French $(2.34 \mathrm{~mm})$ 부속 기구와 0.025 inches $(0.64 \mathrm{~mm})$ 유도선은 병용 사용이 불가능하다. 짧은 유형 단일 풍선 소장내시경에 7 French $(2.34 \mathrm{~mm})$ 부속 기구와 0.035 inches $(0.889 \mathrm{~mm})$ 유도선은 남은 공간이 부족하여 병용 사용이 불가능하다.

\section{2. 긴 유형과 짧은 유형 풍선 소장내시경을 이용한 임상 연구들}

긴 유형 $(2,000 \mathrm{~mm})$ 과 짧은 유형 $(1,520 \mathrm{~mm})$ 단일 풍선 소장내시경의 유효 길이 만을 고려한다면 수술 변형을 가진 환자에서 바터 팽대부 또는 담관 공장 문합부까지의 삽입로가 너무 긴 경우 짧은 유형 단일 풍선 소장내시경이 삽입에 실패할 가능성이 높을 것이라고 예상할 수 있으나 현재까지 나온 임상 결과들은 예상과 다른 결과를 보여주고 있다. 2020년에 발표된 메타분석에 따르면 긴 유형 단일 풍선 소장내시경의 삽입 성공률은 82.9\% (95\% confidence interval [CI] 79.4-85.9), 짧은 유형의 경우에는 92.8\% (95\% CI 90.3-94.7)로 짧은 유형의 삽입 성공률이 더 높다. ${ }^{12}$ 저자들은 연구 대상의 다양성을 고려하여 통계적인 유효성은 언급하지 않고 있으나 $95 \%$ 유효 구간을 고려한다면 유의한 차이가 난다고 볼 수 있다. 선택 삽관 성공률은 긴 유형 단일 풍선 소장내시경 $89.9 \%(95 \% \mathrm{CI}$ 86.7-92.4), 짧은 유형의 경우에는 90.4\% (95\% CI 86.6-93.2)로 차이가 없었다. 전체적인 성공률은 긴 유형 단일 풍선 소장내시경에서 $72.7 \%$ (95\% CI 68.9-76.2)이며, 짧은 유형의 경우에는 $81.8 \%$ (95\% CI 78.3-84.9)로 짧은 유형에서 높았으며, 이는 $95 \%$ 유효 구간을 고려한다면 통계적인 유효성이 있으리라고 판단된다. 결국 짧은 유형 단일 풍선 소장내시경의 삽입 성공률이 높기 때문에 이런 결과가 나온 것으로 보인다.

Table 1. Working length, diameter of channel, and dedicated accessories of various enteroscopes (modified from Krutsri et al."

\begin{tabular}{lccc}
\hline & Working length & Diameter of channel & \multicolumn{1}{c}{ Dedicated accessories } \\
\hline Long single balloon enteroscope & $2,000 \mathrm{~mm}$ & $2.8 \mathrm{~mm}$ & Limited \\
Long double balloon enteroscope & $2,000 \mathrm{~mm}$ & $2.2 / 3.2 \mathrm{~mm}$ & Limitation \\
Short single balloon enteroscope & $1,520 \mathrm{~mm}$ & $3.2 \mathrm{~mm}$ & Almost no limitation \\
Short double balloon enteroscope & $1,560 \mathrm{~mm}$ & $3.2 \mathrm{~mm}$ & Almost no limitation \\
Spiral enteroscope & $1,680 \mathrm{~mm}$ & $3.2 \mathrm{~mm}$ & Almost no limitation \\
\hline
\end{tabular}


부작용은 긴 유형 단일 풍선 소장내시경에서 $6.6 \%(95 \% \mathrm{CI}$ 4.8-9.0), 짧은 유형의 경우에는 6.3\% (95\% CI 4.3-9.0)로 차이가 없었다.

긴 유형과 짧은 유형 이중 풍선 소장내시경을 이용한 연구들에 대한 2021년 메타분석에서는 긴 유형 이중 풍선 소장내시경의 삽입 성공률은 $87 \%$ (95\% CI 80-93), 짧은 유형의 경우에는 96\% (95\% CI 93-99)로 짧은 유형의 삽입 성공률이 더 높지만 통계적인 유효성은 없었다. 전체적인 성공률은 긴 유형 이중 풍선 소장내시경에서 $88 \%$ (95\% CI 76-96), 짧은 유형의 경우에는 96\% (95\% CI 91-100)로 짧은 유형에서 높았으며 또한 통계적인 유효성은 없었다. 부작용은 긴 유형 이중 풍선 소장내시경에서 5\% (95\% CI 2-9), 짧은 유형의 경우에는 4\% (95\% CI 3-7)로 차이가 없었다.

이상의 연구들로 최소한 짧은 유형 단일 또는 이중 풍선 소장내시경이 수술 변형을 가진 환자에서 긴 유형보다 삽입 성공률 및 전체 성공률에서 뒤지지 않는다는 것을 확인할 수 있다. 최근 한 연구에서는 짧은 유형 단일 풍선 소장내시경 성공률에 영향을 주는 인자로 췌장 공장 문합부 협착과 같은 췌장 적응증(odds ratio [OR] 4.35, 95\% CI 1.6-11.4), 첫 번째 시도(OR 6.03, 95\% CI 2.1-16.8), 투명캡 미착용(OR 4.61, 95\% CI 1.4-14.3)을 제시하였다. ${ }^{8}$ 이 결과에 따르면 투명캡 착용이 매우 성공에 중요한 요소이며 첫 번째 시도에 실패하였다고 해도 두 번째 시도에서 성공할 가능성이 있음을 제시해 준다. 투명캡의 유용성은 다른 연구에서도 확인되는데, 소장내시경 선단에 투명캡을 부착한 경우가 부착하지 않은 경우보다 유의하게 소장 삽입 길이가 길다고 보고된 연구도 있으며, ${ }^{13}$ 또 다른 연구는 투명캡을 부착하면 바터 팽대부를 잘 관찰할 수 있는 가능성이 유의하게 증가한다고 보고하였다. ${ }^{14}$ 개인적으로 소장내시경 선단에 투명캡을 부착하면 삽입 속도를 증가시켜 시술 시간을 단축하는 면이 가장 크다고 생각하나 현재까지 이에 대한 임상 연구는 없다.

한편, Kawaguchi 등 $^{15}$ 은 수술 변형이 있는 환자들을 위를 절제한 경우와 위를 절제하지 않은 경우로 나누어 첫 번째 시도에서 짧은 형 단일 풍선 소장내시경을 사용하여 삽입에 실패한 경우 두 번째에 긴 형 단일 풍선 소장내시경을 사용하였을 때 삽입 성공률이 증가하는지를 분석하였는데, 위를 절제한 경우에는 차이가 없으나 위를 절제하지 않은 환자에서 일차 성공률 $60 \%$ 에서 2 차 성공률이 $91 \%$ 로 유의하게 증가함을 보고하였다. ${ }^{15}$

\section{결 론}

짧은 유형 단일 풍선 소장내시경은 긴 유형 단일 풍선 소장내시경에 비하여 유효 길이가 $1,520 \mathrm{~mm}$ 로 짧지만 임상 연구들에 따르면 수술 변형이 있는 대부분 환자에서 바터 팽대부 및 담관 공장 문합부까지 도착하는 데 긴 유형 단일 풍선 소장내시경과 차이가 없다. 또한 성공적인 $\mathrm{ERCP}$ 를 위해서는 다양한 형태의 부속 기구를 제한 없이 사용할 수 있어야 하는데, 국내에서 사용 중인 긴 유형 단일 풍선 소장내시경은 겸자공의 크기가 작고 유효 내시경 길이가 길어서 부속 기구 사용에 제한이 많으나 짧은 유형 단일 풍선 소장내시경은 겸자공의 크기가 크고 유효 내시경 길이가 짧아 거의 제한이 없다. 따라서 $\mathrm{ERCP}$ 가 필요한 수술 변형이 있는 환자에서 짧은 유형 단일 풍선 소장내시경을 먼저 선택하는 것이 바람직하다.

\section{요 약}

전통적으로 수술 변형이 있는 환자에서 소장내시경을 이용한 내시경역행담췌관조영술(ERCP)은 까다롭고 합병증이 높은 검사로 인식되었다. 그러나 최근 연구 결과들은 그렇게 속단할 수 없음을 보여주고 있다. 특히 다양한 소장내시경을 이용한 연구 성적들은 상당히 유망한 결과들을 보여주고 있다. 다양한 소장내시경 중 국내에서 긴 유형 단일 풍선 소장내시경이 $\mathrm{ERCP}$ 에 가장 많이 사용되어 왔는데, 최근 짧은 유형 단일 풍선 소장내시경이 도입되어 사용 가능하게 되었다. 긴 유형과 짧은 유형 단일 풍선 소장내시경을 선택하기전에 크게 2가지 점을 고려할 필요가 있다. 첫째, 긴 유형과 짧은 유형 사이의 구체적인 차이점이 실제 $\mathrm{ERCP}$ 에 어떤 영향을 미치냐는 점이다. 둘째, 두 유형의 단일 풍선 소장내시경을 이용한 임상 연구 결과들에 대한 올바른 접근이다. 결론으로 말하면 짧은 유형 단일 풍선 소장내시경은 $\mathrm{ERCP}$ 가 필요한 대부분의 수술 변형 환자에서 가장 먼저 선택해 볼 수 있다.

국문 색인: 내시경역행담췌관조영술; 수술 변형 구조; 단일 풍선 소장내시경

\section{Conflicts of Interest}

The author has no conflicts to disclose. 


\section{REFERENCES}

1. Freeman ML, Guda NM. ERCP cannulation: a review of reported techniques. Gastrointest Endosc 2005;61:112-125.

2. Chahal P, Baron TH, Topazian MD, Petersen BT, Levy MJ, Gostout CJ. Endoscopic retrograde cholangiopancreatography in post-Whipple patients. Endoscopy 2006;38:1241-1245.

3. Park $\mathrm{CH}$. Endoscopic retrograde cholangiopancreatography in post gastrectomy patients. Clin Endosc 2016;49:506-509.

4. Wang $F, X u B$, Li Q, et al. Endoscopic retrograde cholangiopancreatography in patients with surgically altered anatomy: one single center's experience. Medicine (Baltimore) 2016;95:e5743.

5. Skinner M, Popa D, Neumann H, Wilcox CM, Mönkemüller K. ERCP with the overtube-assisted enteroscopy technique: a systematic review. Endoscopy 2014;46:560-572.

6. Inamdar S, Slattery E, Sejpal DV, et al. Systematic review and metaanalysis of single-balloon enteroscopy-assisted ERCP in patients with surgically altered GI anatomy. Gastrointest Endosc 2015;82:9-19.

7. Anvari S, Lee $Y$, Patro N, Soon MS, Doumouras AG, Hong D. Doubleballoon enteroscopy for diagnostic and therapeutic ERCP in patients with surgically altered gastrointestinal anatomy: a systematic review and meta-analysis. Surg Endosc 2021;35:18-36.

8. Yane K, Katanuma A, Maguchi H, et al. Short-type single-balloon enteroscope-assisted ERCP in postsurgical altered anatomy: potential factors affecting procedural failure. Endoscopy 2017;49:69-74.

9. Ali MF, Modayil R, Gurram KC, Brathwaite CEM, Friedel D, Stavropou- los SN. Spiral enteroscopy-assisted ERCP in bariatric-length Roux-en-Y anatomy: a large single-center series and review of the literature (with video). Gastrointest Endosc 2018;87:1241-1247.

10. Soh JS, Yang DH, Lee SS, et al. Single balloon enteroscopy-assisted endoscopic retrograde cholangiopancreatography in patients who underwent a gastrectomy with Roux-en-Y anastomosis: six cases from a single center. Clin Endosc 2015;48:452-457.

11. Krutsri C, Kida M, Yamauchi H, Iwai T, Imaizumi H, Koizumi W. Current status of endoscopic retrograde cholangiopancreatography in patients with surgically altered anatomy. World J Gastroenterol 2019;25:3313-3333.

12. Tanisaka Y, Ryozawa S, Mizuide M, et al. Status of single-balloon enteroscopy-assisted endoscopic retrograde cholangiopancreatography in patients with surgically altered anatomy: systematic review and meta-analysis on biliary interventions. Dig Endosc 2020 Oct 18. [Epub ahead of print]

13. Hasak S, Lang G, Early D, et al. Use of a transparent cap increases the diagnostic yield in antegrade single-balloon enteroscopy for obscure Gl bleed. Dig Dis Sci 2019;64:2256-2264.

14. Silva LC, Arruda RM, Botelho PFR, et al. Cap-assisted endoscopy increases ampulla of Vater visualization in high-risk patients. BMC Gastroenterol 2020;20:214.

15. Kawaguchi $Y$, Yamauchi $H$, Kida $M$, et al. Failure factors to reach the blind end using a short-type single-balloon enteroscope for ERCP with Roux-en-Y reconstruction: a multicenter retrospective study. Gastroenterol Res Pract 2019;2019:3536487. 